\title{
A ORGANIZAÇÃO DO TRATADO DO ATLÂNTICO NORTE E OS OBSTÁCULOS PARA A COOPERAÇÃO COM AS NAÇÕES UNIDAS
}

\section{L'ORGANISATION DU TRAITÉ DE L'ATLANTIQUE NORD ET LES OBSTACLES À LA COOPÉRATION AVEC LES NATIONS UNIES}

\author{
${ }^{1}$ Marília Figueiredo Álvares Da Silva \\ ${ }^{2}$ Rodrigo Alves Pinto Ruggio
}

\begin{abstract}
RESUMO
A Organização do Tratado do Atlântico Norte - OTAN foi criada em 1949 como um contrapeso ao crescente poder da União Soviética, constituindo-se de uma aliança militar composta por diversos Estados. Após a queda do bloco soviético, a OTAN buscou se adaptar para fazer frente a novas ameaças, tais como o terrorismo global, pirataria, guerra cibernética, operações de manutenção da paz e segurança internacional e, mais recentemente, o ressurgimento da Rússia como uma potência econômica e militar cada vez mais assertiva nas relações internacionais. As bases legais de atuação da aliança estão claramente definidas em seu tratado constitutivo, denominado Tratado de Washington e na Carta das Nações Unidas. Uma análise destes dois documentos conjugada com a análise da diversidade de interesses entre seus membros revela possíveis entraves para a atuação da organização em operações de manutenção da paz e segurança internacional a cargo do Conselho de Segurança da ONU.
\end{abstract}

Palavras-chave: Cooperação otan-onu, Obstáculos, Manutenção da paz e segurança internacional

\begin{abstract}
L'Organisation du Traité de l'Atlantique Nord - OTAN a été créé en 1949 comme un contrepoids à la montée en puissance de l'Union soviétique, de devenir une alliance militaire de divers états. Après la chute du bloc soviétique, l'OTAN a cherché à s'adapter pour faire face aux nouvelles menaces telles que le terrorisme mondial, la piraterie, la cyber-guerre, le maintien de la paix et la sécurité internationales et, plus récemment, la résurgence de la Russie en tant que puissance économique et militaire de plus en plus affirmée dans les relations internationales. Le systeme juridique de l'alliance est clairement définies dans son traité fondateur, connu comme le Traité de Washington et de la Charte des Nations Unies. Une analyse de ces deux documents combinés avec l'analyse de la diversité des intérêts parmi ses membres révèle les obstacles possibles aux activités de l'organisation dans le maintien des opérations de paix et de sécurité internationale en charge de le Conseil de Sécurité de l'ONU.
\end{abstract}

Keywords: La coopération otan-onu, Obstacles, Maintien de la paix et de la sécurité internationale

\footnotetext{
${ }^{1}$ Especialista em Direito de Empresa pela Pontifícia Universidade Católica de Minas Gerais - PUC Minas, Minas Gerais, MG, Brasil. Advogada no escritório Melo Campos Advogados Associados, MELO CAMPOS. E-mail: marilia.fas@hotmail.com

${ }^{2}$ Mestre em Direito pela Pontifícia Universidade Católica de Minas Gerais - PUC Minas, Minas Gerais, MG, Brasil. Professor na Pontifícia Universidade Católica de Minas Gerais, PUC Minas, MG. E-mail:

rodrigoruggio@hotmail.com 


\section{INTRODUÇÃ̃O}

O presente artigo tem como objetivo analisar os obstáculos que se colocam no caminho da cooperação entre a Organização das Nações Unidas - ONU e a Organização do Tratado do Atlântico Norte - OTAN, evidenciando as condicionantes existentes para o seu desenvolvimento, sobretudo no contexto atual de ocorrência de múltiplas crises internacionais, como os conflitos na Ucrânia, Síria e Iraque e a expansão do terrorismo global.

Para tanto, o texto encontra-se estruturado da seguinte forma. No capítulo 2 apresenta-se um breve histórico dos fundamentos por trás da criação das denominadas alianças defensivas no Direito Internacional, para em seguida apresentar o desenvolvimento histórico da OTAN, com destaque para a expansão da aliança e a mudança de escopo com a queda da União Soviética. São abordadas as intervenções promovidas pela aliança, seja em cooperação com as Nações Unidas, seja agindo fora do âmbito da Carta.

O Capítulo 3 examina o direito aplicável às ações empreendidas pelos denominados “Acordos Regionais" previstos na Carta das Nações Unidas e a cujo regramento a OTAN encontra-se subordinada, bem como as regras previstas no Tratado de Washington, que regulam o mecanismo de defesa coletiva da aliança. Destaca-se a possibilidade do uso do direito de veto no seio do Conselho de Segurança da ONU para aprovar ou ratificar uma ação empreendida pela OTAN e a dificuldade de coordenar os interesses dentro da própria aliança diante da necessidade de aprovação por consenso das operações militares que envolvem o uso da força.

Por fim, o Capítulo 4 apresenta a conclusão de que a cooperação entre a ONU e a OTAN em operações de manutenção da paz e segurança internacional não apresenta possibilidade de desenvolvimento em um futuro de curto e longo prazo em razão de dois fatores principais. Primeiro, a dificuldade de coordenação de interesses dos membros permanentes do Conselho de Segurança, tendo em vista a possibilidade do uso do direito de veto. E segundo, a expansão da aliança ocorrida durante a Guerra Fria e até recentemente. Ao evoluir para um acordo regional formado por 28 Estados que se encontram, pelo Tratado de Washington, submetidos ao princípio do consenso para a tomada de decisão, a OTAN passou a estar submetida ao conflito de interesses entre seus membros, que podem apresentar percepções distintas do que seja uma ameaça à paz ou segurança internacional. Ações promovidas pela aliança que possam ter repercussões políticas para qualquer dos membros dificilmente obterão o necessário consentimento. 
A metodologia empregada se alicerçou em pesquisa das normas legais e revisão bibliográfica realizada em fontes doutrinárias.

\section{Breve histórico sobre a Organização do Tratado do Atlântico Norte}

A Organização do Tratado do Atlântico Norte - OTAN foi concebida e projetada como uma aliança militar intergovernamental baseada no princípio da defesa coletiva. Criada por meio de um tratado internacional multilateral, comumente conhecido como Tratado de Washington prevê em seu artigo $5^{\circ}$ que um ataque armado contra um ou mais dos membros na Europa ou na América do Norte será considerado um ataque contra todos, que então deverão agir no direito de legítima defesa reconhecido pela Carta da ONU até que a paz e a segurança estejam restabelecidas. Dispõe ainda que qualquer ação empreendida pela OTAN será imediatamente comunicada ao Conselho de Segurança da ONU e terminará assim que o Conselho tiver adotado as medidas necessárias para restaurar e manter a paz e a segurança internacionais.

\section{Tratado de Washington}

\section{Artigo 5}

As Partes concordam em que um ataque armado contra uma ou várias delas na Europa ou na América do Norte será considerado um ataque a todas, e, consequentemente, concordam em que, se tal ataque armado se verificar, cada uma, no exercício do direito de legítima defesa, individual ou coletiva, reconhecido pelo artigo 51. ${ }^{\circ}$ da Carta das Nações Unidas, prestará assistência à Parte ou Partes assim atacadas, praticando sem demora, individualmente e de acordo com as restantes Partes, a ação que considerar necessária, inclusive o emprego da força armada, para restaurar e garantir a segurança na região do Atlântico Norte.

Qualquer ataque armado desta natureza e todas mais providências tomadas em consequência desse ataque serão imediatamente comunicadas ao Conselho de Segurança. Essas providências terminarão logo que o Conselho de Segurança tiver tomado as medidas necessárias para restaurar e manter a paz e a segurança internacionais. (COIMBRA, 1949).

Tratados de aliança defensiva são comuns no Direito Internacional, sendo possível constatar sua existência ao longo da história como um acordo unindo um ou mais Estados contra um inimigo comum, conforme destaca a obra de Hugo Grócio: 
3. De igual modo, na aliança de guerra, se concorda em fornecer socorro igual em cavaleiros, soldados de infantaria, navios para todo tipo de guerra, o que os gregos chamam de "לv $\mu \mu \alpha \chi \imath \alpha$ " e que Tucídides explica por "ter os mesmos amigos e os mesmos inimigos", expressão que se encontra com frequência em Tito Lívio. O mesmo valia também somente para proteger as fronteiras, o que era chamado de " $\varepsilon \pi \mu \mu \iota \alpha$ ". Ainda para uma guerra determinada ou contra inimigos determinados ou contra todos na verdade, mas excetuandose os aliados de parte e outra, como no tratado entre os cartagineses e os macedônios que se encontra em Políbio. Assim é que os habitantes de Rodes prometeram por tratado a Antígono e a Demétrio de lhes fornecer auxílios contra qualquer dos inimigos, exceto Ptolomeu. Um tratado igual pode se referir também, como dissemos, a outros objetos. Por exemplo, proibir que um dos contratantes possua fortalezas nas fronteiras do outro, que um proteja os súditos do outro, que um conceda passagem ao inimigo do outro. (GROTIUS, 2004, p. 655).

No mesmo sentido, o Professor da Faculdade de Direito da Universidade de Lisboa, Antônio Pedro Barbas Homem, em sua obra "História das Relações Internacionais: O Direito e as Concepções Políticas na Idade Moderna”, explica o desenvolvimento do denominado “direito das alianças" evidenciando a prática de associação entre os Estados com vistas à defesa mútua:

Nos tratadistas da época em estudo aliança tem igualmente o sentido de liga ou ainda de confederação. Para os tratadistas políticos, as alianças constituíam instrumentos importantes de associação entre Estados, sobretudo quando a sua dimensão exígua exigia os compromissos necessários à sua conservação. No desenvolvimento do direito das alianças distinguem-se as alianças entre iguais e desiguais, consoante a dimensão ou importância dos Estados, e as alianças defensivas e ofensivas, consoante a sua finalidade a proteção mútua ou uma ofensiva militar perante um inimigo comum. (HOMEM, 2003, p. 311).

CASELLA, ACCIOLY e SILVA (2010) inserem a formação de alianças defensivas no contexto do direito de defesa e conservação, afirmando que o direito de conservação abrange todos os atos necessários à defesa do estado contra inimigos internos ou externos, tais como a adoção de leis penais, a organização de tribunais repressivos, a prática de medidas de ordem policial, a expulsão de estrangeiros nocivos à ordem ou à segurança públicas, a proibição da entrada de indesejáveis e a organização da defesa nacional. 
No que tange à OTAN, o escopo inicial justificador de sua formação foi o crescente poder da União Soviética e o temor de uma possível invasão da Europa. Com o fim da Segunda Guerra Mundial e a bipolarização do sistema internacional entre as duas superpotências, União Soviética e Estados Unidos, o temor de um novo conflito na Europa serviu de base para a criação da aliança. O poder militar combinado dos Estados - Membros seria a ferramenta de uma política de dissuasão adotada como forma de conter e limitar a esfera de influência soviética durante os anos da Guerra Fria.

Peter Calvocoressi destaca que:

\begin{abstract}
A criação da OTAN foi uma afirmação da dissolução da aliança dos tempos de guerra. Ela se baseava no temor à agressão russa, potencializado por uma revolta contra a natureza da dominação dos russos no Leste Europeu, a frustração que se transformava em hostilidade nas questões alemãs, a exposição da Europa Ocidental como resultado de danos de guerra e desmobilização, e o fracasso em internacionalizar o controle da energia atômica. (CALVOCORESSI, 2011, p. 33).
\end{abstract}

A aliança militar em que se baseia a OTAN foi composta inicialmente por 12 Estados - Membros envolvendo países da Europa Central, Ocidental e os Estados Unidos, prevendo no artigo 10 de seu tratado a possibilidade de expansão do bloco, que conta atualmente com 28 Estados Membros.

A expansão pode ser dividida em seis fases principais, três ocorreram durante a Guerra Fria e três depois. Turquia e Grécia foram os primeiros novos membros a reforçar a estratégia de contenção da organização em 1952. A Alemanha Ocidental aderiu em 1955 dando ensejo à criação do Pacto de Varsóvia pela União Soviética, uma aliança defensiva que englobou oito Estados comunistas das Europas Central e Oriental criando um contrapeso à expansão da OTAN, conforme explica Celso D. de Albuquerque Mello:

O Pacto de Varsóvia, firmado em 1955 pelos representantes da URSS, Bulgária, Hungria, Romênia, Albânia, Polônia, Tcheco-Eslováquia e República Democrática Alemã, é uma resposta do bloco soviético à OTAN e à UEO. Objetivos: a) estabelecer entre os seus signatários uma aliança defensiva; b) assistência coletiva; c) cria um comando unificado dos exércitos colocados à sua disposição; d) o desarmamento e a interdição das armas nucleares. A Albânia se retirou em 1968, e em 1990 a Alemanha Oriental.

Entre os seus órgãos estão: a) Comitê Consultivo Político, onde estão representados os Estados - membros; b) um Secretariado; c) Comissão Permanente. Tem ainda a sua organização militar. 
A sede era em Varsóvia.

O Pacto de Varsóvia foi extinto em 1991. (MELLO, 2004, p.752).

A terceira fase de expansão da OTAN durante a Guerra Fria envolveu a adesão da Espanha em 1982. As três etapas finais da expansão ocorreram em 1999, 2004 e 2009 englobando antigos países comunistas. Em 1999 consolidou-se a adesão da Hungria, Polônia e República Checa, três países componentes do extinto Pacto de Varsóvia. Em 2004 ocorreu a adesão da Bulgária, Estônia, Letônia, Lituânia, Romênia, Eslováquia e Eslovenia e em 2009 as adições mais recentes, Albânia e Croácia. São, portanto, Estados-Membros da aliança, a Albânia, Alemanha, Bélgica, Canadá, Croácia, Dinamarca, Espanha, Estados Unidos, França, Grécia, Holanda, Islândia, Itália, Luxemburgo, Noruega, Portugal, Reino Unido, Turquia, Hungria, Polônia, República Checa, Bulgária, Estônia, Letônia, Lituânia, Romênia, Eslováquia e Eslovênia.

Com a queda do Muro de Berlim em 1989 e a atenuação da ameaça soviética, a OTAN teve de remodelar-se para fazer frente a novos desafios de segurança, voltando sua atenção para temas diversos como o terrorismo global, pirataria, guerra cibernética, proliferação nuclear, operações de manutenção da paz e segurança internacional a cargo da ONU, dentre outros.

Acerca deste último ponto, cumpre destacar que o fim da Guerra Fria foi significativo para o desenvolvimento das relações entre a ONU e a OTAN. Ambas as organizações mudaram significativamente com o colapso da União Soviética. A OTAN que tinha um objetivo de segurança bastante estreito passa a atuar em outras frentes ampliando seu escopo de atuação para além da Europa.

$\mathrm{Na}$ ONU as tensões da Guerra Fria entre os Estados Unidos e a União Soviética comprometeram a eficácia do Conselho de Segurança das Nações Unidas que frequentemente ficava paralisado em razão do uso do direito de veto. Essa dinâmica impedia qualquer tentativa de cooperação da OTAN com as operações de manutenção da paz e segurança internacional da ONU, razão pela qual durante este período a ONU e a OTAN raramente interagiram de forma significativa.

Embora as organizações possuam objetivos distintos, o desenvolvimento das relações entre ambas tem evoluído significativamente nas duas últimas décadas conforme se pode verificar com a crise na Bósnia no início de 1990. Por meio da Resolução 816 (1993) do Conselho de Segurança a ONU recorreu à OTAN para implementar um embargo de armas contra todos os Estados da antiga Iugoslávia e para implementar as sanções contra a 
República Federal da Iugoslávia (Sérvia e Montenegro). As aeronaves da OTAN, principalmente, garantiram a existência de uma zona de proibição de voo sobre a Bósnia a partir de abril de 1993, conhecida como “Operation Deny Flight" e em fevereiro de 1994 quatro aviões de combate foram abatidos por aeronaves da OTAN por violarem referida zona (SHAW, 2010).

As aeronaves da aliança também ofereceram apoio aéreo às atividades da UNPROFOR (Força de Proteção da ONU) a partir de junho de 1993, e, a partir de abril de 1994, destacou-se apoio aéreo para a proteção dos funcionários da ONU nas denominadas "zonas de segurança", cujo conceito pode ser encontrado na Resolução 824 (1993) do Conselho de Segurança. Entre 1994 e 1995, a OTAN realizou ataques aéreos a pedido da ONU em diversas ocasiões, prestando apoio à UNPROFOR, conforme se pode verificar pelas Resoluções 908 (1994) e 958 (1994) do Conselho de Segurança (SHAW, 2010).

Malcon N. Shaw (2010) destaca que em razão do Acordo de Paz de Dayton, firmado em novembro de 1995, uma tropa de 60 mil homens iniciou operações na Bósnia sob o comando da OTAN, com o objetivo de implementar o acordo:

A ação foi autorizada pelo Conselho de Segurança nos termos do Capítulo VII, mediante a Resolução 1031 (1995), que transferiu a autoridade da UNPROFOR (Força de Proteção da ONU) para a IFOR (Força de Implementação). Esta última foi em pouco tempo substituída pela SFOR (Força de Estabilização). A SFOR é comandada pela OTAN, mas conta com a participação de Estados que não são membros desta. (SHAW, 2010, p. 955).

Esta cooperação entre a ONU e a OTAN foi duramente criticada na intervenção desta última no Kosovo em 1999, quando a aliança realizou bombardeios na região sem a autorização do Conselho de Segurança. Em 1997, a República Federal da Iugoslávia, liderada pelo presidente Slobodan Milosevic, deu início a violenta repressão de uma milícia rebelde e de seus partidários na província essencialmente muçulmana do Kosovo. A ONU reagiu um ano depois por meio de seu secretário-geral Kofi Annan que destacou o fato da força estar sendo usada de forma "indiscriminada e desproporcional" contra civis, com o cometimento de “estarrecedoras atrocidades” (BYERS, 2007).

Em 23 de setembro de 1998 o Conselho de Segurança adotou a Resolução 1199. Agindo expressamente no contexto do Capítulo VII, o Conselho exigia que o governo Milosevic pusesse fim a suas "ações repressivas contra populações pacíficas" do Kosovo, resolvendo a situação sem recurso à força. O Conselho também advertia que, se Milosevic 
não atendesse, seriam consideradas novas iniciativas e medidas adicionais para manter ou restabelecer a paz e a segurança na região.

Um mês depois, o Conselho de Segurança adotou a Resolução 1203, saudando a assinatura, entre Belgrado e a Organização para a Segurança e a Cooperação na Europa (OSCE), de um acordo para a criação de uma missão de verificação da paz no Kosovo. O Conselho de Segurança enfatizava a necessidade de garantir a segurança dos membros da missão da OSCE, afirmando que a situação no Kosovo constituía uma ameaça à paz e à segurança. Em seguida, invocando expressamente o Capítulo VII, o Conselho afirmava que em caso de emergência, poderia ser necessária uma iniciativa para garantir a segurança e liberdade dos membros da missão.

Michael Byers (2007) destaca que o Conselho de Segurança nesta resolução dava a entender a possibilidade de que fosse necessário intervir para resgatar pessoal da OSCE, mas nada dizia que pudesse ser interpretado como autorização para uma ação militar. $\mathrm{O}$ autor trabalha a questão no contexto das denominadas "Autorização implícita e ambiguidade intencional" presentes em diversas resoluções do Conselho de Segurança da ONU.

Em 24 de março de 1999, sem que uma nova resolução tivesse sido adotada pelo Conselho de Segurança da ONU, a OTAN deu início a uma campanha de ataques aéreos contra alvos não só no Kosovo como também na Sérvia e Montenegro, gerando severas críticas por parte da sociedade internacional:

Muito pouco se alegou em matéria de justificativas jurídicas para esses ataques aéreos, embora a maioria dos países envolvidos considerasse relevante que o Conselho de Segurança tivesse identificado a situação no Kosovo como ameaça à paz e à segurança, nas Resoluções 1199 e 1203. Até onde chegaram de todo a adiantar alguma justificativa, as potências interventoras argumentavam que, uma vez tendo o Conselho de Segurança identificado uma ameaça e exigido ação frente a um Estado "problemático", os membros das Nações Unidas estão implicitamente no dever de garantir que a vontade do Conselho seja cumprida. A Guerra do Kosovo foi considerada ilegal pela Rússia, a China e muitos países em desenvolvimento. Desse modo, embora o argumento da existência de uma autorização implícita tenha sido acenado durante a Guerra do Kosovo, foram muito poucos - inclusive entre aqueles que sustentavam esta argumentação - os que o levaram muito a sério. (BYERS, 2007, p. 60).

O Juiz da Corte Interamericana de Direitos Humanos, Antônio Augusto Cançado Trindade, em sua obra "Direito das Organizações Internacionais" tece duras críticas à atuação 
da OTAN no Kosovo, qualificando-a como contrária à Carta da ONU e ao próprio Tratado da OTAN:

\begin{abstract}
O fato é que o Conselho de Segurança, no referido caso do Kosovo, não havia autorizado a ação armada contra a Iugoslávia, da forma como se efetuou. Não há como escapar da constatação de que o Conselho de Segurança jamais autorizou o referido bombardeio, que se deu, pois, em violação da Carta da ONU, e inclusive do próprio Tratado da OTAN (de 1949), porquanto nenhum membro da OTAN havia sido atacado para que se recorresse ao uso da força armada. Há necessariamente que combater os despotismos (como o do regime de Belgrado contra seu próprio povo), mas dentro do Direito e de conformidade com a normativa internacional aplicável. Não podia a OTAN haver-se sobreposto, em sua estratégia, à própria Carta das Nações Unidas; o episódio revela a necessidade premente de modificação desta última, para proceder a uma profunda reforma da estrutura e operação do Conselho de Segurança.
\end{abstract}

No cas d'espèce, a OTAN buscou encontrar na resolução 1.244 (1999) do Conselho de Segurança, adotada a posteriori, uma forma de uma intervenção armada estribada na política de poder. Definitivamente, might is not right. Um pacto militar de defesa coletiva não pode arrogar-se em paladino da comunidade internacional. Ao contrário, assim agindo, presta um desserviço à construção de um ordenamento jurídico internacional verdadeiramente a serviço da comunidade internacional. Não se pode desencadear uma operação de cunho pretendidamente humanitário mediante a intervenção de um pacto militar de um grupo de países, à margem da Carta das Nações Unidas. E o Conselho de Segurança da ONU não pode deixar-se ambiguamente utilizar, de modo a prestar-se a este tipo de ação unilateral. (TRINDADE, 2003, p. 838).

Apesar de este fato demonstrar algum grau de competição entre as organizações no que tange à manutenção da paz e segurança internacional e revelar os riscos de que um acordo regional possa atuar de forma unilateral e em desrespeito à normativa internacional, atualmente a OTAN tem assumido uma ampla gama de missões com o apoio das Nações Unidas.

A partir de 2014, a OTAN prossegue com cinco missões, sendo elas, operações de manutenção da paz no Kosovo; patrulhas antiterrorismo no mar mediterrâneo; antipirataria no Golfo de Áden e ao largo do Corno de África; assistência à União Africana no Sudão; e a prioridade da aliança, a Força Internacional de Assistência à Segurança (ISAF) da missão no Afeganistão. Sobre esta última é interessante destacar que após os ataques de 11 de setembro de 2001 nos Estados Unidos perpetrados pela rede terrorista Al Qaeda, à época baseada no Afeganistão, foi a primeira vez desde a fundação da OTAN que o artigo $5^{\circ}$ de seu tratado, que versa sobre o mecanismo de defesa coletiva, foi colocado em prática. Pouco tempo depois que 
s forças lideradas pelos Estados Unidos derrubaram o regime Talibã em Cabul, o Conselho de Segurança da ONU por meio da Resolução 1386 (2001) autorizou uma Força Internacional de Assistência à Segurança para apoiar o novo governo afegão. A OTAN assumiu oficialmente o comando da ISAF em 2003, assumindo seu primeiro compromisso operacional para além da Europa.

Kent J. Kille, do College of Wooster e Ryan C. Hendrickson, da Eastern Illinois University, em artigo intitulado "Nato and The United Nations: Debates and Trends in Institutional Coordination"1 destacam que: "With these missions the political and security linkages between the UN and NATO have become progressively more evident, and seem likely to increase in the short-and long-term future"2 (KILLE, HENDRICKSON, 2014, p. 29). Apesar dos professores acima afirmarem que é provável um aumento da cooperação entre ambas as organizações em um futuro de curto e longo prazo, somos do entendimento contrário, na medida em que a existência de certas condicionantes colocam obstáculos no caminho desta parceria, conforme será demonstrado ao longo deste trabalho.

Por fim, cumpre destacar o papel desempenhado pela OTAN no conflito ocorrido na Líbia em 2011 que culminou com a derrubada do governo de Muammar al-Gaddafi.

Em 17 de março de 2011 o Conselho de Segurança da ONU aprovou a Resolução 1973 (2011) autorizando os Estados Membros a agir de forma individual ou por meio de acordos ou arranjos regionais para tomar todas as medidas necessárias para proteger a população civil na Líbia. Da mesma forma estabeleceu uma zona de exclusão aérea com vistas a cumprir com o objetivo de proteção dos civis que à época estavam sofrendo ataques da força aérea Líbia.

Em 25 de março de 2011 a OTAN assumiu o comando da operação denominada UNIFIED PROTECTOR implementando a zona de exclusão aérea e supervisionando o embargo de armas também fixado pela Resolução 1973. A participação da OTAN nesta missão foi aprovada pelo Conselho do Atlântico Norte, órgão deliberativo da organização no qual todos os Estados Membros estão representados e onde as decisões são tomadas por consenso.

\footnotetext{
${ }^{1}$ OTAN e as Nações Unidas: Debates e Tendências na Coordenação Institucional.

${ }^{2}$ Com essas missões as relações políticas e de segurança entre a ONU e a OTAN tornaram-se progressivamente mais evidentes, e parece provável que aumentem no futuro de curto e longo prazo.
} 
Esta e as demais missões conjuntas ONU-OTAN refletem uma interação entre ambas as organizações para o atendimento de interesses mútuos, mas que não necessariamente representam uma evolução da parceria de modo a torná-la constantemente envolvida em questões relacionadas à manutenção da paz e segurança internacional, conforme será abordado no capítulo seguinte.

\section{ANÁLISE DAS CONDICIONANTES PARA A ATUAÇÃO DA OTAN EM COOPERAÇÃO COM AS NAÇÕES UNIDAS}

A análise das condicionantes que se colocam no caminho da Organização do Tratado do Atlântico Norte deve-se iniciar pelo estudo de dois documentos principais, a Carta das Nações Unidas e o Tratado de Washington, uma vez que uma ação militar empreendida pela aliança e em conformidade com o Direito Internacional somente pode ser levada a efeito nos termos previstos na Carta da ONU, conforme será demonstrado.

A ONU substituiu a extinta Liga das Nações, sendo concebida como uma organização internacional voltada para a solução de questões universais, sendo que seu preâmbulo deixa claro que a paz e a segurança internacionais são os objetivos primordiais da organização, como haviam sido, sem sucesso, de sua predecessora. Nesse sentido, a Carta enfatiza no artigo 24 a responsabilidade primária do Conselho de Segurança na manutenção da paz e segurança internacional:

\section{Carta das Nações Unidas}

\section{Artigo24}

1. A fim de assegurar pronta e eficaz ação por parte das Nações Unidas, seus Membros conferem ao Conselho de Segurança a principal responsabilidade na manutenção da paz e segurança internacionais e concordam em que no cumprimento dos deveres impostos por essa responsabilidade o Conselho de Segurança aja em nome deles.

2. No cumprimento desses deveres, o Conselho de Segurança agirá de acordo com os Propósitos e Princípios das Nações Unidas. As atribuições específicas do Conselho de Segurança para o cumprimento desses deveres estão enumeradas nos Capítulos VI, VII, VIII e XII.

3. O Conselho de Segurança submeterá relatórios anuais e, quando necessário, especiais à Assembleia Geral para sua consideração. (SARAIVA, 2012).

No entanto, a contribuição para a manutenção da paz e segurança internacional por organizações regionais é permitida pela Carta da ONU no seu Capítulo VIII, artigos 52, 53 e 
54, que versam sobre os Acordos Regionais, constituindo a base legal de cooperação ONUOTAN. Conforme dispõe o artigo 52, nada na Carta impede a existência de acordos ou de entidades regionais, destinadas a tratar dos assuntos relativos à manutenção da paz e segurança internacional que forem suscetíveis de uma ação regional, desde que tais acordos ou entidades regionais e suas atividades sejam compatíveis com os Propósitos e Princípios das Nações Unidas. (SARAIVA, 2012).

Importante destacar o artigo 53 da Carta da ONU que destaca expressamente a possibilidade de cooperação na manutenção da paz e segurança internacional entre as organizações:

\section{Carta das Nações Unidas}

\section{Artigo 53}

1. O Conselho de Segurança utilizará, quando for o caso, tais acordos e entidades regionais para uma ação coercitiva sob a sua própria autoridade. Nenhuma ação coercitiva será, no entanto, levada a efeito de conformidade com acordos ou entidades regionais sem autorização do Conselho de Segurança, com exceção das medidas contra um Estado inimigo, como está definido no parágrafo $2^{\circ}$ deste Artigo, que forem determinadas em consequência do Artigo 107 ou em acordos regionais destinados a impedir a renovação de uma política agressiva por parte de qualquer desses Estados, até o momento em que a Organização possa, a pedido dos Governos interessados, ser incumbida de impedir toda nova agressão por parte de tal Estado.

2. O termo Estado-inimigo, usado no parágrafo 1 deste Artigo, aplica-se a qualquer Estado que, durante a Segunda Guerra Mundial, foi inimigo de qualquer signatário da presente Carta. (SARAIVA, 2012).

E ainda, afirma o artigo 54 da Carta da ONU que "O Conselho de Segurança será sempre informado de toda ação empreendida ou projetada de conformidade com os acordos ou entidades regionais para a manutenção da paz e da segurança internacionais". (SARAIVA, 2012). A análise conjunta destes dispositivos não deixa dúvidas acerca da subordinação da OTAN em relação à ONU no que tange à responsabilidade primordial do Conselho de Segurança para a tomada de ações coercitivas com vistas à manutenção da paz e segurança internacional, apesar da doutrina não ser unânime acerca deste entendimento (KILLE, HENDRICKSON, 2014).

Malcon N. Shaw, em sua obra "Direito Internacional” destaca referido entendimento nos seguintes termos: “O artigo 53 observa que o Conselho de Segurança poderá utilizar, quando oportuno, esses sistemas ou agências para a implementação de ações coercitivas, 
sempre sob a autoridade do próprio Conselho. Sem a autorização do Conselho de Segurança, não são possíveis ações coercitivas regionais". (SHAW, 2010, p.950). No mesmo sentido, Celso D. de Albuquerque Mello enfatiza: “A OTAN tem, em relação à ONU, um aspecto subsidiário". (MELLO, 2004, p.753).

Cumpre registrar que a definição de "acordos ou organizações regionais" prevista na Carta da ONU foi deixada propositalmente em aberto para assegurar certo grau de flexibilidade, de modo que o termo possa abranger um amplo leque de organizações regionais e não só aquelas criadas estritamente para a cooperação em matéria de defesa como a OTAN. (SHAW, 2010).

Ocorre que, apesar de subordinada à ONU, é importante destacar a possibilidade de atuação da OTAN fora do veto do Conselho de Segurança, quando esta atuação ocorrer com base no artigo 51 da Carta, que versa sobre o direito de legítima defesa. Estabelece o artigo 51:

\section{Carta das Nações Unidas}

Artigo 51

Nada na presente Carta prejudicará o direito inerente de legítima defesa individual ou coletiva no caso de ocorrer um ataque armado contra um membro das Nações Unidas, até que o Conselho de Segurança tenha tomado as medidas necessárias para a manutenção da paz e segurança internacionais. As medidas tomadas pelos membros no exercício desse direito de legítima defesa serão comunicadas imediatamente ao Conselho de Segurança e não deverão, de modo algum, atingir a autoridade e a responsabilidade que a presente Carta atribui ao Conselho para levar a efeito, em qualquer tempo, a ação que julgar necessária à manutenção ou ao restabelecimento da paz e da segurança internacionais. (SARAIVA, 2012).

A referência no artigo ao direito de legítima defesa coletiva constitui o permissivo legal de uso da força empreendido por alianças militares regionais como a OTAN. Malcon N. Shaw (2010) destaca que "organizações como a OTAN e o Pacto de Varsóvia, criadas após a Segunda Guerra Mundial, baseiam-se especificamente no direito de legítima defesa coletiva nos termos do artigo 51 ".

A Corte Internacional de Justiça se pronunciou sobre os requisitos essenciais ao uso coletivo da força no acordão de 27 de junho de 1986, proferido no caso Nicarágua. Ela salientou que o direito à legítima defesa coletiva tinha suas raízes no direito consuetudinário e 
que seu exercício dependia de uma declaração prévia por parte do Estado interessado de que este era vítima de um ataque armado, juntamente com um pedido de assistência. (SHAW, 2010).

Kent J. Kille e Ryan C. Hendrickson (2014) explicam que na criação da Carta da ONU em 1945, diversos estados, especialmente na América Latina, defenderam a possibilidade de que as organizações regionais poderiam responder a um ataque nos termos do artigo 51 sem necessidade de aprovação formal do Conselho de Segurança. Este entendimento foi reiterado quando uma proposta canadense que propunha a necessidade de aprovação formal do Conselho de Segurança, antes da força ser utilizada em resposta a um ataque, foi derrotada.

A legítima defesa coletiva já foi invocada em algumas ocasiões, inclusive, por meio da utilização de organizações regionais, como por exemplo: pelos Estados Unidos, quando de sua intervenção no Líbano, em 1958 e no Vietnã, a partir de 1967; pela União Soviética para justificar operações na Hungria em 1956 e na Checoslováquia em 1968, ambas à sombra do Pacto de Varsóvia, e no Afeganistão em 1979; pelo Reino Unido, em 1964, para justificar a intervenção contra o Iêmen em favor da Federação da Arábia do Sul. (BRANT, 2008). E ainda, conforme já visto, a OTAN invocou pela primeira vez em sua história a legítima defesa coletiva prevista no artigo $5^{\circ}$ de seu tratado após os ataques de 11 de setembro de 2001 realizados pela rede terrorista $\mathrm{Al}$ Qaeda.

O artigo 51 da Carta da ONU é expressamente mencionado no artigo $5^{\circ}$ do Tratado de Washington, conforme visto no Capítulo 2 deste artigo, destacando a possibilidade de utilização da força armada pela OTAN, se necessário, "no exercício do direito de legítima defesa, individual ou coletiva, reconhecido pelo artigo $51^{\circ}$ da Carta das Nações Unidas". (COIMBRA, 1949).

Por outro lado, o artigo 53 da Carta da ONU, conforme visto acima, dispõe que “nenhuma ação coercitiva será, no entanto, levada a efeito de conformidade com acordos ou entidades regionais sem autorização do Conselho de Segurança...”. E o artigo 54 afirma que “o Conselho de Segurança será sempre informado de toda ação empreendida ou projetada de conformidade com os acordos ou entidades regionais para manutenção da paz e da segurança internacionais". (SARAIVA, 2012).

Por óbvio, a ação coercitiva a que se refere o artigo 53 é aquela que não se enquadra no direito de legítima defesa coletiva assegurado no artigo 51 da Carta, pois esta apenas exige comunicação ao Conselho de Segurança e eventual aprovação em momento posterior à ação 
empreendida, já que conforme dispõe o artigo 51 "nada na presente Carta prejudicará o direito inerente de legítima defesa individual ou coletiva no caso de ocorrer um ataque armado contra um membro das Nações Unidas, até que o Conselho de Segurança tenha tomado as medidas necessárias para a manutenção da paz e segurança internacionais". (SARAIVA, 2012). Essa ambiguidade, portanto, presente na Carta da ONU quando conjugada com o artigo $5^{\circ}$ do Tratado da OTAN constitui o permissivo legal autorizador de uma ação coercitiva pela aliança sem a autorização do Conselho de Segurança. Esta autorização ou implementação de medidas para restabelecimento da paz pelo Conselho de Segurança poderia vir em momento posterior à ação empreendida, mas, dependendo do contexto, poderia ser vetada por um dos membros permanentes, impedindo a atuação do Conselho e colocando a questão mais grave, de que uma guerra possa ser travada em legítima defesa, conforme explicam Nguyen Quoc Dinh, Patrick Daillier e Alain Pellet:

Com efeito, este órgão desempenha um papel decisivo na aplicação do art. $51^{\circ}$. O direito de legítima defesa não pode ser invocado senão enquanto o Conselho de Segurança não tenha tomado as medidas necessárias para manter a paz e ele deve ser exercido tendo informado imediatamente o Conselho das medidas tomadas.

Reencontramos as mesmas características na ordem internacional. O caráter provisório e controlado da legítima defesa resulta dos elementos processuais invocados pelo art. $51^{\circ}$, o seu caráter subsidiário deduz-se da responsabilidade principal do Conselho, expressão da comunidade internacional, na manutenção da paz, e do caráter temporário do exercício da legítima defesa.

$\mathrm{Na}$ prática, todas as insuficiências do sistema de segurança coletiva não podem senão atenuar o caráter subsidiário e temporário, portanto controlado, do exercício da legítima defesa. Quando, paralisado por um veto ou pelas divergências de opinião dos seus membros, o Conselho de Segurança não esteja na situação de qualificar uma situação ou de tomar medidas corretivas, ele deixa um campo aberto ao princípio da legítima defesa. E sabemos quanto é frequente esta hipótese. (DINH, DAILLIER, PELLET, 2003, p. 961).

Neste ponto surge o primeiro obstáculo para a cooperação entre a ONU e a OTAN, a coordenação de interesses dentro do Conselho de Segurança. A dificuldade de coordenação destes interesses poderia ocorrer não somente com relação à aprovação posterior de uma ação coercitiva empreendida em legítima defesa, mas também no caso de ações coercitivas pretendidas pelo Conselho de Segurança no cumprimento de sua função primordial de manutenção da paz e segurança internacional. 
A adoção de medidas relacionadas à manutenção da paz pelo Conselho no âmbito do Capítulo VII da Carta exige a determinação prévia da existência de alguma ameaça à paz, ruptura da paz ou ato de agressão, conforme definido no artigo 39. Alcançar essa definição é fundamental para colocar em prática o sistema de segurança coletiva da ONU, passando a adoção de medidas que empreguem o uso da força pelos Estados Membros ou por meio de acordos regionais como a OTAN.

Nesse contexto, surge a questão de como definir uma ameaça à paz, ruptura da paz ou ato de agressão. Malcon N. Shaw explica que a dinâmica desta definição, submetida que está à coordenação de interesses dos membros permanentes, é uma das causas do fracasso do Conselho de Segurança em lidar com sua atribuição primordial de manutenção da paz:

A resposta que nasceu da experiência prática é que tal definição depende das circunstâncias de cada caso. Depende também da relação que os cinco membros permanentes do Conselho (Reino Unido, EUA, Rússia, China e França) tenham com o tema considerado, já que o voto desfavorável de qualquer dos membros permanentes é suficiente para bloquear todas as resoluções do Conselho, com exceção das meramente processuais. Esse poder de veto tem sido uma das principais causas do fracasso do Conselho em sua competência de preservar a paz e a segurança internacionais. (SHAW, 2010, p.923).

Essa questão é reveladora do primeiro obstáculo à cooperação ONU-OTAN na medida em que se o caso envolver interesses de algum membro permanente, certamente que uma resolução pretendida pelo órgão poderá esbarrar no direito de veto destes membros e a história da ONU está repleta de exemplos de uso do direito de veto diante de uma situação de ameaça ou ruptura da paz, paralisando a atuação do Conselho.

A falta de tropas próprias por parte da ONU torna interessante para a organização a utilização da OTAN como ferramenta para os mandatos de manutenção da paz e segurança internacional, como por exemplo, ao implementar um bloqueio aéreo e/ou o monitoramento de um embargo de armas com vistas à proteção da população civil.

Entretanto, em se tratando da utilização da Organização do Tratado do Atlântico Norte para a execução de algum mandato a possibilidade de que o membro permanente Rússia utilize seu direito de veto é uma realidade que não se pode ignorar, tendo em vista todo o contexto histórico que permeia a criação e desenvolvimento da aliança e o sucessor da extinta União Soviética. Sobretudo na atualidade, na qual a crise na Ucrânia tem retomado uma antiga preocupação da OTAN, a possibilidade de um confronto direto com a Rússia. 
Brooke A. Smith-Windsor, da NATO Defense College $e^{3}$, explica a dinâmica por trás da utilização pela ONU da OTAN em operações de manutenção da paz e a relação com a Rússia:

Faculdade de Defesa da OTAN.

Com relação às grandes potências, considerando a animosidade histórica da União Soviética para a OTAN, as atitudes russas têm importância fundamental no desenvolvimento de uma relação de trabalho viável entre a ONU e a OTAN:

Com a Rússia em apoio, ou pelo menos neutra, uma ação concertada da OTAN e a ONU é mais provável de ocorrer. Sem essa cooperação, os reflexos da velha rivalidade das superpotências soviética-americana e um fracasso em alcançar um consenso no Conselho de Segurança são distintamente possíveis.

Desde o fim da Guerra Fria, o apoio ou pelo menos a aquiescência tem, como mencionado acima, autorizado um número crescente de operações da OTAN em apoio a resoluções do Conselho de Segurança da ONU que pedem a execução de ações para manter a paz e a segurança internacionais. Mas as atitudes positivas dos russos não podem ser dadas como certas, como o caso de Kosovo em 1999 destaca nitidamente. A resposta imediata da Rússia a Declaração Conjunta mencionada ONU-OTAN 2008 é igualmente demonstrativa a este respeito. Embora reconhecendo que a cooperação entre a ONU e as organizações regionais foi, em geral, "uma coisa normal e necessária", o chanceler Sergei Lavrov na época criticou a negociação do acordo por sua falta de transparência e invasão de áreas consideradas uma prerrogativa dos Estados soberanos. (SMITH-WINDSOR, 2011, p. 31, tradução nossa ${ }^{4}$ ).

\footnotetext{
${ }^{4}$ With respect to the Great Powers, considering the historic animosity of the Soviet Union to NATO, Russian attitudes have fundamental bearing on the development of a viable working relationship between the UN and NATO:

With Russia in support, or at least neutral, concerted NATO-UN action is more likely to occur. Without such cooperation, reflections of the old Soviet-US superpower rivalry and a failure to achieve consensus in the Security Council are distinctly possible.

Since the Cold War's end, such support or at least acquiescence has, as alluded to above, authorized a growing number of NATO operations in support of UN Security Council resolutions calling for enforcement action to maintain international peace and security. But positive Russian attitudes cannot be taken for granted, as the Kosovo case of 1999 starkly underscores. The immediate Russian response to the aforementioned UN-NATO 2008 Joint Declaration is equally demonstrative in this regard. While Acknowledging that cooperation between the UN and regional organizations was in general "a normal and necessary thing", Foreign Minister Sergei Lavrov at the time lambasted the accord's negotiation for its lack of transparency and encroachment of areas considered the prerogative of sovereign states.
} 
A coordenação entre organizações regionais e a ONU é importante para auxiliar no objetivo maior de manutenção da paz e segurança internacional, mas esta coordenação de interesses muitas vezes esbarra em considerações de natureza política.

Esta situação foi emblemática durante a Guerra Fria, a bipolarização do sistema internacional entre as duas superpotências fazia com que conflitos regionais adquirissem proporções transcontinentais já que o objetivo era a supremacia ideológica global defendida por Moscou e Washington, fato este que prejudicou sobremaneira a atuação das Nações Unidas.

Nesse contexto, qualquer ação coercitiva para manutenção da paz pretendida pela ONU com a utilização da OTAN, forçosamente esbarrava no direito de Veto da extinta União Soviética, paralisando a atuação do Conselho de Segurança.

José Luiz Singi Albuquerque explica o desenvolvimento desse contexto histórico ao comentar o artigo 53 da Carta da ONU que versa sobre a possibilidade de utilização pelo Conselho de Segurança dos organismos regionais, conforme explicado acima:

Em um cenário em que tensões regionais foram aproveitadas como espaço de manobra de conflitos mundiais, parece compreensível que o Conselho tivesse dificuldades para que seus membros chegassem a um consenso sobre uma ação qualquer e, particularmente, sobre uma ação que envolvesse o uso de um organismo regional.

Em última análise, a execução de medidas coercitivas por uma entidade regional contra um país acabava quase sempre esbarrando na questão do alinhamento automático e da radicalização da política do "amigo ou inimigo". Assim, se uma superpotência tivesse interesse estratégico em apoiar a ação de uma organização regional contra certo país, então, provavelmente, a outra superpotência tenderia a querer apoiar o país ameaçado seguindo a lógica do "inimigo do meu inimigo é meu amigo".

Contudo, esse tipo de sujeição da Carta das Nações Unidas à dinâmica interativa dos jogos de poder e de interesse na sociedade internacional não é exclusividade do artigo 53. Só é de lamentar que instrumento tão promissor, acabe tendo tão pouco uso. (BRANT, 2008, p. 828).

Após a Guerra Fria, apesar da cooperação entre a ONU e a OTAN ter ocorrido conforme já delineado, nos dias atuais uma Rússia ressurgente e cada vez mais assertiva em suas relações internacionais, a exemplo do conflito na Ucrânia, onde Moscou dá suporte aos rebeldes separatistas pró-russos, bem como a anexação da Crimeia, tem naturalmente levantado a questão da inviabilização da cooperação entre ambas as organizações para lidar com tais ameaças a paz. Qualquer tentativa de utilização da OTAN para a implementação de 
uma ação coercitiva sob mandato da ONU para lidar com estas crises certamente vai esbarrar no veto Russo dentro do Conselho de Segurança.

Noutro giro, destaca-se que a dificuldade para a cooperação ONU-OTAN em ações coercitivas não se encontra apenas na aprovação de uma Resolução no seio do Conselho de Segurança. A coordenação de interesses dentro da própria OTAN para uma atuação sob os auspícios da ONU também é difícil de conseguir.

José Luiz Singi Albuquerque destaca que:

A coordenação de interesses dentro do Conselho de Segurança já é difícil. O mesmo geralmente se passa no âmbito dos organismos regionais. Por isso, uma ação integrada entre órgãos universais e regionais multiplica os fatores de complicação que precisam ser enfrentados. (BRANT, 2008, p. 828).

Com sede em Bruxelas, na Bélgica, a OTAN é uma aliança baseada em consenso, no qual as decisões refletem a vontade coletiva dos Estados membros. A decisão tomada por consenso é um acordo alcançado pela vontade comum, uma decisão que é aceita por cada país membro. Isto significa que quando uma "decisão OTAN" é anunciada, ela expressa a vontade coletiva de todos os Estados que sejam membros da aliança. (NATO, 2014).

O consenso na tomada de decisão significa que não há nenhuma votação na OTAN. As consultas realizar-se-ão até que uma decisão que seja aceitável por todos é alcançada. Às vezes, os países membros concordam em discordar sobre um problema. Em geral, esse processo de negociação é rápido, pois os membros consultam-se mutuamente em uma base regular, conforme disposto no artigo $4^{\circ}$ do Tratado de Washington e, portanto, muitas vezes, já conhecem e entendem a posição do outro com antecedência. Facilitar este processo de consulta é uma das principais funções do Secretário Geral da Organização, atualmente o norueguês Jens Stoltenberg. O consenso tem sido aceito como a única base para a tomada de decisões no âmbito da OTAN desde a criação da aliança em 1949. (NATO, 2014).

Embora a aplicação do princípio do consenso na tomada de decisões no seio da OTAN atribua certa legitimidade para suas ações, já que refletem a vontade coletiva de 28 Estados soberanos, é também seu ponto fraco. Obter unanimidade no Conselho do Atlântico Norte de forma a autorizar uma ação coercitiva em cooperação com a ONU não é simples, pois os Estados membros possuem diversos interesses e que, muitas vezes, são distintos. Dependendo dos atores envolvidos em uma situação de crise em que a OTAN seja cogitada a 
cooperar com a ONU, a obtenção do consenso para a tomada de decisão pode ser de difícil obtenção:

\begin{abstract}
A moderna força da OTAN - 28 Estados membros combinados em um acordo de defesa coletiva - é também o seu calcanhar de Aquiles. Os membros da organização, invariavelmente, têm imperativos geográficos diferentes, diferentes ameaças percebidas e falta um inimigo unificador, por enquanto. A unanimidade é fundamental, não só para a tomada de decisão, mas também para orientar a organização. Infelizmente, a OTAN tem dificuldade em chegar a um acordo sobre as medidas mais básicas, que tem sido uma receita para uma falha estratégica e estagnação, deixando poucas oportunidades para o desenvolvimento militar coeso em uma direção concordada. Qualquer missão potencial que poderia ter repercussões políticas contra um único membro é improvável de ocorrer. Como resultado, a OTAN tem lutado para permanecer relevante no mundo pós - Guerra Fria. Em vez de ser um elo de poder global, a OTAN mais frequentemente tem sido relegada a ser uma ferramenta de conveniência, usada quando a vontade política existe e o momento é adequado. (STRATFOR, 2014, tradução nossa).
\end{abstract}

A dificuldade de obtenção de consenso entre os Estados membros da OTAN para autorizarem uma ação coercitiva sob os auspícios da ONU pode ser mais bem visualizada na hipótese de uma eventual ação de manutenção da paz envolvendo a atual crise na Ucrânia. Neste caso, ambos os obstáculos para a cooperação ONU-OTAN citados neste trabalho provavelmente incidiriam. Em primeiro lugar, qualquer tentativa de aprovação de uma Resolução no Conselho de Segurança da ONU que pudesse dar ensejo à autorização de uma ação coercitiva para manutenção da paz utilizando a OTAN certamente seria barrada pelo uso do direito de veto pelo membro permanente Rússia, dado o seu envolvimento no conflito e o contexto histórico de rivalidade existente entre Moscou e a OTAN. E, em segundo lugar, ainda que fosse possível obter a aprovação de uma ação coercitiva no Conselho de Segurança da ONU, a aprovação desta ação por consenso no Conselho da OTAN também seria difícil de conseguir. A razão para esta falta de consenso seria meramente política e atrelada a questões econômicas.

Conforme explicam Robert D. Kaplan e Eugene Chausovsky:

Um quarto de toda a energia para a Europa vem da Rússia, mas essa estatística é uma média para todo o continente. Assim, à medida que se move sucessivamente da Europa Ocidental para a Europa Central e para a Europa Oriental este percentual sobe drasticamente. O gás natural é mais importante do que o petróleo nessa história, mas vamos considerar o petróleo primeiro. 
A Rússia é um dos principais produtores de petróleo em todo o mundo e tem entre as maiores reservas, com vastos depósitos na Sibéria tanto ocidental quanto oriental. Fundamentalmente, a Rússia está agora a investir na tecnologia necessária para preservar a sua posição como um importante centro de energia durante anos e décadas, embora seja uma questão em aberto se os níveis atuais de produção podem ser mantidos no longo prazo. A porta de entrada principal da Rússia na Europa para exportar seu petróleo (e gás natural) é Belarus, no norte e no sul da Ucrânia. A rede de gasodutos Druzhba leva o petróleo russo através de Belarus para a Polônia e a Alemanha, no norte e no sul através da Ucrânia para a Europa Central e nos Balcãs, bem como para a Itália. A Rússia certamente tem influência na Europa por conta de seu petróleo, e tem ocasionalmente usado seu petróleo como meio de pressão política sobre a Bielorrússia e a Ucrânia. Mas se movendo para o oeste na Europa, as negociações sobre o petróleo russo são geralmente sobre a oferta e preços, não fatores políticos. É realmente com o gás natural que a energia torna-se uma ferramenta política útil para a Rússia.

A Rússia é, depois dos Estados Unidos, simplesmente o maior produtor de gás natural em todo o mundo, com trilhões de metros cúbicos de reservas. A Europa recebe 25 por cento do seu gás natural da Rússia, no entanto, mais uma vez, esse número aumenta drasticamente na Europa Central e Oriental; em geral, quanto mais próximo de um país é a Rússia, mais dependente é do gás natural russo. Europa Central (com exceção da Roménia, que tem suas próprias reservas) atrai cerca de 70 por cento do gás natural que consome da Rússia. Belarus, Bulgária e os Estados bálticos dependem da Rússia para 90-100 por cento de suas necessidades de gás natural. Rússia tem usado essa dependência para influenciar a tomada de decisões desses Estados, oferecendo condições vantajosas para os Estados que cooperam com Moscou, enquanto a cobrança de preços mais elevados e, ocasionalmente, cortando o fornecimento completamente para aqueles que não o fazem. Isso se traduz em poder geopolítico real, ainda que o Pacto de Varsóvia não exista mais. (KAPLAN, CHAUSOVSKY, 2013, tradução nossa ${ }^{5}$ ).

Nesse contexto delicado de dependência energética da Europa com relação à Rússia é forçoso reconhecer as limitações da OTAN para uma ação coercitiva autorizada pela ONU que envolva interesses geopolíticos russos. A obtenção de consenso no Conselho da OTAN provavelmente esbarraria na oposição da Alemanha, que possui uma forte parceria energética com a Rússia, bem como de países da Europa central e Oriental que igualmente são dependentes da energia provinda de Moscou, como a Polônia e a Bulgária.

\footnotetext{
${ }^{5}$ One-quarter of all energy for Europe comes from Russia, but that statistic is an average for the whole continent; thus, as one moves successively from Western Europe to Central Europe to Eastern Europe that percentage rises dramatically. Natural gas is more important than oil in this story, but let us consider oil first. Russia is among the top oil producers worldwide and has among the largest reserves, with vast deposits in both western and eastern Siberia. Crucially, Russia is now investing in the technology necessary to preserve its
} 
position as a major energy hub for years and decades to come, though it is an open question whether current production levels can be maintained in the long term. Russia's primary gateway to Europe for oil (and natural gas) is Belarus in the north and Ukraine in the south. The Druzhba pipeline network takes Russian oil through Belarus to Poland and Germany in the north and in the south through Ukraine to Central Europe and the Balkans, as well as to Italy. Russia certainly has influence in Europe on account of its oil, and has occasionally used its oil as a means of political pressure on Belarus and Ukraine. But moving westward into Europe, negotiations over Russian oil are generally about supply and pricing, not political factors. It is really with natural gas that energy becomes a useful political tool for Russia.

Russia is, after the United States, simply the largest producer of natural gas worldwide, with trillions of cubic meters of reserves. Europe gets 25 percent of its natural gas from Russia, though, again, that figure rises dramatically in Central and Eastern Europe; generally, the closer a country is to Russia, the more dependent it is on Russian natural gas. Central Europe (with the exception of Romania, which has its own reserves) draws roughly 70 percent of the natural gas it consumes from Russia. Belarus, Bulgaria and the Baltic states depend on Russia for 90-100 percent of their natural gas needs. Russia has used this dependence to influence these states' decision-making, offering beneficial terms to states that cooperate with Moscow, while charging higher prices and occasionally cutting off supplies altogether to those that don't. This translates into real geopolitical power, even if the Warsaw Pact no longer exists.

Esta lógica de dificuldade de obtenção de consenso no Conselho da OTAN para a aprovação de uma medida coercitiva pode ser reproduzida em qualquer contexto no qual existam interesses dos Estados membros da aliança em jogo, o que dificulta a tomada de decisões por parte da organização, impactando a possibilidade de atuação conjunta entre a ONU e a OTAN em questões de manutenção da paz e segurança internacional.

Desse modo, embora a cooperação entre ambas as organizações tenha se desenvolvido significativamente após a Guerra Fria, obstáculos ainda persistem. A dificuldade de coordenação de interesses no Conselho de Segurança da ONU para a aprovação de uma Resolução que autorize uma ação coercitiva de manutenção da paz por meio da OTAN é uma realidade que impacta seriamente as possibilidades de atuação da organização, tendo em vista a possibilidade de uso do direito de veto previsto no artigo 27 da Carta.

De igual modo, a adoção de uma ação coercitiva pela OTAN tem que ser aprovada por consenso de todos os 28 Estados membros da aliança, que podem apresentar interesses divergentes dependendo dos atores envolvidos em uma situação de ameaça à paz, razão pela qual a dificuldade de obtenção deste consenso no seio da aliança é uma realidade que pode impactar significativamente sua atuação.

\section{CONCLUSÃO}

A Organização do Tratado do Atlântico Norte foi criada em 1949 como forma de conter o poderio da extinta União Soviética, sendo atualmente a principal e mais forte aliança militar existente. Nos últimos vinte anos a OTAN evoluiu para enfrentar ameaças globais que 
vão desde a pirataria ao largo do Corno de África até os insurgentes do Talibã nas montanhas do Afeganistão. A possibilidade de atuação da aliança para além da Europa e fora das hipóteses delineadas pelo artigo $5^{\circ}$ do Tratado de Washington viabilizou a cooperação com as Nações Unidas em questões de manutenção da paz e segurança internacional.

Ocorre que, embora a cooperação entre ambas as Organizações tenha aumentado significativamente após a Guerra Fria, obstáculos ainda persistem para a efetivação de uma relação mais estreita em assuntos de manutenção da paz e segurança internacional.

Em primeiro lugar, qualquer ação coercitiva de manutenção da paz implementada pela OTAN sob os auspícios do Conselho de Segurança da ONU deve envolver a coordenação de interesses entre os membros permanentes que, conforme previsão do artigo 27 da Carta, podem utilizar o direito de veto para bloquear a aprovação de tal medida. Dado o contex to histórico que permeia a criação e desenvolvimento da aliança, a probabilidade de uso do direito de veto pelo membro permanente Rússia é uma hipótese bastante provável. Da mesma forma, o membro permanente China, que juntamente com a Rússia não é um Estado membro da OTAN no Conselho de Segurança, também é um elemento a ser considerado no possível bloqueio de uma ação coercitiva a cargo da OTAN.

Em segundo lugar, a coordenação de interesses dentro da própria OTAN representa um obstáculo significativo à cooperação entre ambas as organizações. Todas as decisões da OTAN são tomadas por consenso, após discussão e consulta entre os países membros. Alcançar este consenso em torno de uma ação coercitiva de manutenção da paz que usará recursos e naturalmente promoverá a exposição dos Estados membros que muitas das vezes possuem interesses divergentes não é fácil.

O tamanho e a complexidade da aliança dificultam qualquer capacidade de tomar decisões rápidas e em grande escala. Cada membro da aliança tem seus próprios interesses, que não podem estar em perfeito alinhamento com a visão de mundo e os objetivos da OTAN e da ONU. Em uma situação de crise na qual a OTAN possa atuar sob o mandato da ONU, questões de ordem política e econômica podem moldar a decisão dos Estados membros da aliança e o consenso necessário para colocar a OTAN em ação não ser alcançado.

A análise destas condicionantes revela que uma expansão da cooperação entre a ONU e a OTAN em operações de manutenção da paz e segurança internacional no contexto do Capítulo VII da Carta será difícil de obter em um futuro de curto e longo prazo, ficando a aliança do norte relegada a atuações pontuais e servindo mais como instrumento de dissuasão militar para seus membros. 


\section{REFERÊNCIAS}

BRANT, Leonardo Nemer Caldeira. Comentário à Carta das Nações Unidas. Belo Horizonte: CEDIN, 2008.

BYERS, Michael. A Lei da Guerra. Direito Internacional e Conflito Armado. Rio de Janeiro: Record, 2007.

CALVOCORESSI, Peter. Política mundial a partir de 1945. Trad. Roberto Cataldo Costa. Porto Alegre: Penso, 2011.

COIMBRA, Universidade de. Tratado do Atlântico Norte. 1949. Disponível em:

http://www.fd.uc.pt/CI/CEE/OI/NATO/Tratado_NATO.htm. Acesso em 15 de jul. 2014.

DINH, Nguyen Quoc; DAILLER, Patrick; PELLET, Alain. Direito Internacional Público. 2. ed. Lisboa: Fundação Calouste Gulbenkian, 2003.

GROTIUS, Hugo. O Direito da Guerra e da Paz. Trad. Ciro Mioranza. Ijuí: Editora Unijuí, 2004.

HOMEM, Antônio Pedro Barbas. História das Relações Internacionais: O Direito e as Concepções Políticas na Idade Moderna. Coimbra: Editora Almedina, 2003.

KENT, J. Kille; HENDRICKSON, Ryan C. NATO and The United Nations: Debates and Trends in Institutional Coordination. Disponível em: http://www.natolibguides.info/library. Acesso em 16 de jul. 2014.

MELLO, Celso D. de Albuquerque. Curso de Direito Internacional Público. Volume 1. Rio de Janeiro: Renovar, 2004.

NATO. Consensus decision-making at NATO. Disponível em: http://www.nato.int/cps/en/natolive/topics_49178.htm. Acesso em 18 de jul. 2014.

KAPLAN, Robert D; CHAUSOVSKY, Eugene. Pipelines of Empire. 2013. Disponível em: www.stratfor.com. Acesso em 20 de dez. 2013.

SARAIVA. Legislação de Direito Internacional. $5^{a}$ ed. São Paulo: Saraiva, 2012. Colaboração de Luiz Roberto Curia, Livia Céspedes e Juliana Nicoletti.

SHAW, Malcolm. Direito Internacional. Trad. Marcelo Brandão Cipolla, Lenita Ananias do Nascimento, Antônio de Oliveira Sette-Câmara. São Paulo: Martins Fontes, 2010.

TRINDADE, Antônio Augusto Cançado. Direito das Organizações Internacionais. Belo Horizonte: Del Rey, 2003.

SMITH-WINDSOR, Brooke A. Misery Makes for Strange Bedfellows: The Future of the UN-NATO. The UN and NATO: Forward from The Joint Declaration. Roma, Itália:

Deltamedia artigrafiche srl, 2011. 
STRATFOR. NATO: The Current State of Play. Disponível em: www.stratfor.com. Acesso em 20 de jul. 2014. 